\title{
IMPLEMENTASI PEMBAKUAN PERISTILAHAN PERKOMPUTERAN DALAM BAHASA INDONESIA UNTUK MAHASISWA SI 18A4 FIKOM UNIVERSITAS DUTA BANGSA SURAKARTA
}

\author{
Mira Erlinawati dan Aan Nurcholis M \\ Universitas Duta Bangsa Surakarta \\ Email: mira_erlinawati@udb.ac.id dan annur.awwal@gmail.com
}

\section{Abstract}

The aim of this research is (1) know the meaning of standardization of terms in Indonesian for SI 18A4 Student (2) Knowing the importance of computerized terms in Indonesian for SI 18A4 students (3) Knowing the importance of the term computerization in Indonesian for SI $18 A 4$ students. This type of qualitative analysis research only focuses on showing the meaning, descriptive or explanation of the data in their respective parts and is more often indicated in the form of words or sentences rather than in the form of numbers or comparisons in a data. The research location chosen was Surakarta Duta Bangsa University (Faculty of Computer Science). Data collection techniques include structured interviews, questionnaires, and literature studies. The qualitative method basically uses an inductive approach, i.e. data is collected, analyzed, abstracted and theories will emerge related to Indonesian standardization. The type of data and data sources used are primary data and secondary data. The results of the study, according to respondents, the function of defining standardization of computer terms into Indonesian is very important. So with this, the respondents were able to distinguish standardization of computer terms and those that had never been used. And when respondents work on assignments in lectures they have changed and applied standardization of terms in accordance with and based on guidance from educators. So that respondents are able to easily implement it. Transferring the function of the meaning of standardization of computer term to Indonesian is very important in terms of learning or lecturing and standardization of the term computer to Indonesian really requires guidance from experts, especially those who teach in their fields.

Keywords: Language Standardization, Computer Terminology.

\section{Abstrak}

Tujuan penelitian ini yakni (1) Mengetahui pemaknaan pembakuan istilah komputer ke Bahasa Indonesia untuk mahasiswa SI 18A4 (2) Mengetahui pentingnya istilah perkomputeran dalam Bahasa Indonesia untuk mahasiswa SI 18A4 (3) Mengetahui penerapan istilah perkomputeran dalam Bahasa Indonesia untuk mahasiswa SI 18A4. Jenis penelitian analisis kualitatif hanya fokus pada penunujukkan makna, deskriptif atau penjelasan data pada bagiannya masingmasing dan lebih sering ditunjukkan dengan berupa kata-kata atau kalimat daripada dalam bentuk angka-angka atau perbandingan pada sebuah data. Lokasi penelitian 
yang dipilih yakni Universitas Duta Bangsa Surakarta (Fakultas Ilmu Komputer). Teknik pengumpulan data meliputi wawancara terstruktur, kuesioner dan studi pustaka. Metode kualitatif pada dasarnya menggunakan pendekatan induktif, yaitu data dikumpulkan, dianalisis, diabstraksikan dan akan muncul teori-teori yang berkaitan dengan pembakuan Bahasa Indonesia. Jenis data dan sumber data yag digunakan yakni data primer serta data sekunder. Hasil penelitian yakni Menurut responden alih fungsi pemaknan pembakuan istilah computer ke Bahasa Indonesia sangat penting. Sehingga dengan adanya hal tersebut responden mampu membedakan pembakuan istilah komputer dan yang belum pernah menggunakan. Dan ketika responden mengerjakan tugas di perkuliahan mereka sudah merubah dan menerapkan pembakuan istilah sepengatuhuan dan berdasarkan bimbingan dari pendidik. Sehingga responden mampu dengan mudah untuk mengimplementasikannya. Alih fungsi pemaknaan pembakuan istilah computer ke Bahasa Indonesia sangat penting dalam hal pembelajaran atau perkuliahan serta pembakuan istilah computer ke Bahasa Indonesia sangat memerlukan bimbingan dari para ahli khususnya yang mengajar di bidangnya.

Kata kunci: Pembakuan Bahasa, Peristilahan Komputer.

\section{Pendahuluan}

Peristilahan dalam Bahasa Indonesia merupakan hal yang sangat penting yang diterapkan dalam sebuah bahasa. Sebuah bahasa tentunya mempunyai istilah tertentu dalam mengungkapkan suatu bidang tertentu (Setiawati, 2016). Demikian juga halnya dengan bahasa Indonesia. Bahasa Indonesia menggunakan istilah tertentu untuk mengungkapkan hal atau bidang tertentu. Istilah dalam hal khusus dapat diartikan sebagai frasa yang dipakai sebagai nama yang dengan cermat mengungkapkan makna konsep, proses, keadaan, atau sifat yang khas dalam bidang ilmu pengetahuan, teknologi, dan seni.

Perkembangan teknologi khususnya yang terjadi di indonesia terjadi sangat dinamis. Perkembangan tersebut tentu saja berdampak pada segala bidang, seperti ekonomi, kesehatan, sosial dan tentunya pada bidang pendidikan (Cholik, 2017). Dalam hal ini, Perpaduan kemajuan teknologi komputer dan teknologi komunikasi telah menciptakan berbagai kosakata/istilah baru di bidang tertentu. Kosakata atau istilah yang dapat digunakan dalam bahasa asing dapat diserap ke dalam Bahasa Indonesia berdasarkan penggunaan bahasa tersebut. Pengalihan kosakata/istilah bidang ilmu itu ke dalam bahasa Indonesia, kalau tidak secepatnya dilakukan, akan menghadapi kendala. Tidak demikian halnya dengan kata/istilah yang baru masuk dalam kehidupan masyarakat langsung dialihkan ke dalam bahasa Indonesia dan diperkenalkan kepada masyarkat pengguna bahasa Indonesia. Kata/istilah itu langsung diterima dan digunakan oleh masyarakat. Oleh karena itu, pengalihan kata/istilah asing ke dalam bahasa Indonesia harus dilakukan secepat-cepatnya agar istilah asing tersebut tidak lebih dahulu memasyarakat. Dan sehingga dapat menggunakan bahasa yang baku dan efektif (Rizkiansyah \& Rustono, 2017).

Pertumbuhan penggunaan internet di Indonesia, sebagian besar memang menggunakan Bahasa Indonesia yang secara langsung dapat mempengaruhi penggunaan 
Bahasa Indonesia dalam internet. Hal yang tentunya menarik dari fenomena tersebut yakni bagaimana dapat berpengaruh ke bahasa lain, terutama bahasa lain dan bahasa inggris, Komunikasi melalui komputer internet di dunia syber dapat dikatakan sebagai genre baru dalam berkomunikasi bahasa komputer.

\section{Metode Penelitian}

Menurut (Mahsun., 2011) mendeskripsikan bahwa anlaisis kualitatif dapat dikhususkan sebagai makna penggambaran objek dan disertai dengan penjelasan dan dapat berupa uraian suatu kalimat dan dapat berupa data suatu penelitian yang telah dilakukan. Data Teknik Pengumpulan dengan menggunakan wawancara terstruktur, kuesioner dan studi pustaka.

Metode kualitatif pada dasarnya menggunakan pendekatan induktif, yaitu data dikumpulkan, dianalisis, diabstraksikan dan akan muncul teori-teori yang berkaitan dengan pembakuan Bahasa Indonesia sebagai penemuan penelitian kualitatif (Lexy. J.Moeloeng, 2009).

\section{Hasil dan Pembahasan}

\section{Alih fungsi Pemaknaan Pembakuan Istilah Komputer ke Bahasa Indonesia}

Dalam Bahasa Indonesia terdapat istilah komputer yang didasarkan pada Pedoman Umum Ejaan Bahasa Indonesia dan pembentukan istilah. Oleh karena itu maka diperlukan pula dipakai ketentuan berikut yang merupakan pelengkap khusus Pedoman Umum Pembentukan Istilah. Bahasa sumber pembentukan istilah komputer adalah bahasa Inggris yang dipakai sebagai bahasa dasar pengembangan perkomputeran. Pemadanan istilah asing ke dalam bahasa Indonesia dilakukan berdasarkan beberapa ketentuan sebagai berikut.

a. Istilah asing yang dapat dipadankan dengan bahasa Indonesia yang umum. Contoh:

delete padanan kata menghapus (kata baku dalam Bahasa Indonesia)

b. Istilah asing dipadankan dengan bahasa Indonesia yang tidak lazim. Contoh: scan padanan kata yakni memindai dan menggunanakan bahasa baku sehingga mudah untuk dipahami.

c. Istilah asing dipadankan dengan bahasa serumpun yang lazim. Contoh:

Homepage yang berarti halaman yang pada saat itu dibuka.

Background berartikan latar belakang

d. Istilah asing dipadankan dengan bahasa serumpun yang tidak lazim. Contoh: download unduh dan jika dalam Bahasa Indonesia mengambil.

Account dalam bahasa Indonesia yaitu rekening

e. Istilah asing diserap ke dalam bahasa Indonesia:

1) Tanpa melalui proses penyesuaian ejaan. Contoh:

Internet juga berarti internet dalam pembakuan Bahasa Indonesia

2) Melalui penyesuaian ejaan. Contoh:

access yang diserap ke Indonesia menjadi akses 
3) Melalui penyesuaian lafal. Contoh:

manager menjadi manajer

bar-code menjadi kode batang

base menjadi basis

batch menjadi sekelompok dokumen yang di proses

4) Melalui penyesuaian ejaan dan lafal. Contoh:

architecture menjadi arsitektur yang beradasarkan ejaan dan lafal yang digunakan ketika pengucapannya.

5) Melalui penambahan vokal pada akhir kata yang hanya berupa satu suku kata, sekaligus dengan penyesuaian ejaan. Contoh:

fact menjadi fakta, sehingga hanya sekadar ditambah vocal pada akhir suku kata saja.

\section{Pentingnya Istilah Perkomputeran dalam Bahasa Indonesia}

Pembentukan istilah dapat diperhatikan dalam pemanfaatan kosakata yang baik dan benar untuk Bahasa Indonesia. Yang meliputi beberapa hal yakni.

a. Penggunaan istilah dapat dipilih merupakan frasa yang tepat untuk mengungkapkan konsep dan yang tidak menyimpang dari makna itu,

b. Istilah yang dipilih adalah kata yang singkat di antara pilihan yang tersedia yang mempunyai rujukan sama.

c. Penggunaan istilah dalam perkomputeran mempunyai makna yang sama.

Terdapat pedoman khusus penggunaan istilah perkomputeran dalam Bahasa Indonesia sebagai berikut.

a. Keefektifan Penggunaan Kata

Istilah komputer dapat menyediakan kosakata Bahasa Indonesia dan dapat digunakan sebagai upaya yang digunakan dalam kebahasaan untuk mengefektifkan penyususna karya tulis bahasa Indonesia. Dan bersifat beradasarkan pola persyaratan yakni tepat, singkat dan jelas.

Bentuk terakhir benar menurut tata bahasa Inggris, tetapi menyalahi tata kaidah kalimat bahasa Indonesia baku. Oleh karena itu, istilah Indonesia yang dibakukan adalah bentuk tunggal. Jadi, ada 'data' sebagai padanan datum yang dianggap tunggal, dan baru kalau diperlukan, ada bentuk 'data-data' untuk padanan data.

b. Kata Baku atau Istilah baku

Istilah yang dapat dihasilkan berdasarkan Pedoman Khusus Pembentukan Istilah Komputer ini merupakan istilah resmi, sehingga harus dipakai dalam setiap tulisan dan dokumen resmi. Adapun pemapanan pembakuan dan pemakaiannya ditentukan berdasarkan keberterimaannya oleh masyarakat umum.

c. Kepoliglotan orang Indonesia atau dapat menggunakan beberapa Bahasa

Bangsa Indonesia pada dasarnya bersifat polyglot dalam pemakian bahasa. Oleh karena itu, penggunaan istilah yang berasal dari bahasa asing asal 'tampak' seperti bahasa Indonesia tidak akan merupakan masalah. Dalam 
percakapan lisan 'didel' dibenarkan dipakai di samping 'dihapus'. Akan tetapi, untuk bahasa tulis sebaiknya dipakai istilah 'dihapus'. Karena merupakan bahasa yang formal atau baku.

\section{Implementasi Istilah Perkomputeran dalam Bahasa Indonesia untuk Mahasiswa SI 18A4}

Hasil jawaban kuesioner yang diberikan pada responden (Mahasiswa Universitas Duta Bangsa Surakarta SI 18A4) yang mengimplementasikan istilah perkomputeran dalam Bahasa Indonesia sebagai berikut.

a. Secara umum responden belum pernah mengetahui atau mendengar mengenai istilah perkomputeran dalam Bahasa Indonesia. Sehingga dengan adanya tuturan dari pendidik khususnya mahasiswa dapat mengetahui dan memaparkan yang di iringi penjelasan di setiap point tersebut.

b. Responden dalam pembelajaran khususnya Bahasa Indonesia ada yang sudah mampu dan menerapkan dalam pembelajaran di MKU tersebut. Sehingga dengan adanya di materi pembelajaran responden mengetahui dan dapat memahami dengan baik dalam hal istilah perkomputeran. Responden juga sudah menerapkan pembakuan istilah di pembelajaran yang di terima pada saat perkuliahan.

c. Menurut responden alih fungsi pemaknaan pembakuan istilah komputer ke Bahasa Indonesia sangat penting. Sehingga dengan adanya hal tersebut responden mampu membedakan pembakuan istilah komputer dan yang belum pernah menggunakan. Dan ketika responden mengerjakan tugas di perkuliahan mereka sudah merubah dan menerapkan pembakuan istilah sepengatuhuan dan berdasarkan bimbingan dari pendidik. Pendidik selalu ikut serta dalam mengembangkan dan menerapkan pembakuan bahasa. Sehingga responden mampu dengan mudah untuk mengimplementasikannya.

d. Terdapat juga responden yang memang belum pernah mengetahui dan membaca mengenai implementasi pembakuan bahasa. Tetapi hal tersebut tidak menyurutkan responden untuk dapat mencari dari berbagai sumber referensi yang mereka ketahui. Karena menurut mereka pembakuan bahsa yang berhubungan dengan istilah computer sangat penting jika di terapkan dalam semua mata kuliah. Dan sumber yang mereka cari tidak hanya dari buku tetapi dari media internet yang ada hubungannya dengan pembakuan bahasa. Karena menurut mereka itu hal yang sangat penting mengingat mereka berada di lingkungan perkuliahan. Karena secara umum beberapa dari responden ada yang memang belum sama sekali tidak menerapkan pembakuan tersebut. Padahal pembakuan dalam pembelajaran Bahasa Indonesia sangat penting dan wajib di gunakan dalam berbagai mata kuliah.

e. Alih fungsi pemaknaan pembakuan istilah computer ke Bahasa Indonesia sangat penting dalam hal pembelajaran atau perkuliahan serta pembakuan istilah computer ke Bahasa Indonesia sangat memerlukan bimbingan dari 
para ahli khususnya yang mengajar di bidangnya. Alih fungsi pemaknaan pembakuan istilah computer yang ingin di terapkan di pembelajaran harus sesuai dengan standard pemahaman akademik mahasiswa. Bimbingan dan arahan sangat diperlukan ketika melakukan pembakuan bahasa. Karena sebenarnya secara umum responden mengetahu arti dan maksud tetapi belum mampu untuk menerapkan ke bahasa yang baku di dalam pembelajaran Bahasa Indonesia.

f. Secara umum responden mengaku jika mereka memang mengetahu mengenai pembakuan istilah computer dalam Bahasa Indonesia mereka dapat berbagi ilmu dengan teman sejawatnya atau teman perkuliahan khususnya teman seangkatan mereka. Karena dengan adanya berbagi ilmu mereka semua dapat menggunakan peristilahan di semua perkuliahan yang mereka terapkan. Karena sesuai dengan pembakuan bahasa sangat diperlukan di dalam pembelajaran. Khususunya di perguruan tinggi. Berdasarkan implementasi pembelajaran yang sudah dilaksanakan. Responden masih dalam tahap proses belajar untuk menggunakan pembakuan perisitilahan tersebut. Dengan adanya pembakuan istilah computer ke Bahasa Indonesia, bertujuan untuk mengaplikasikan EYD dan pembakuan bahasa dapat dipergunakan sebagaimana mestinya. Untuk merubah menjadi kebiasaan menulis dengan menggunakan pembakuan Bahasa Indonesia memang membutuhkan latihan dalam menerapkan pembakuan tersebut. Responden selama ini hanya sekadar mengerjakan tugas dan mengetik saja, tetapi tidak pernah menghiraukan semua pembakuan istilah Bahasa Indonesia. Pembakuan peristilahan perkomputeran untuk Bahasa Indonesia sangat penting keberadaanya. Apalagi mayoritas responden ketika masih duduk di bangku SMA bukan dari khusus jurusan Bahasa Indonesia tetapi terdapat berbagai jurusan sebelum masuk ke perguruan tinggi ini. Sangat disayangkan jika mahasiswa hanya sekadar mampu menggunakan bahasa perkomputeran saja. Sebenarnya bahasa perkomputeran atau yang berada di tampilan menu layar laptop hanya sekadar sinonim arti Bahasa Indonesia.

g. Mahasiswa seharusnya mengetahui pembelajaran tentang istilah istilah perkomputeran secara umum dan khusus, sehingga apabila mahasiswa sudah mampu membedakan istilah perkomputeran dalam hal umum dan khusus. Mahasiswa setidaknya dapat mengimplementasikan di perkuliahan dengan tepat berdasarkan dari ilmu yang mereka dapatkan. Misalnya, dalam hal yang umum mahasiswa tersebut dapat dengan mudh untuk melaksanakan pada saat di ruang lingkup masyarakat. Tetapi, jika dalam khusus berarti dalam hal perkuliahan atau pembelajaran yang dilaksanakan di Universitas tersebut. Untuk mengetahui hal tersebut memang perlu adanya pembelajaran yang secara langsung bertujuan untuk mendapatkan perbedaan masingmasing istilah perkmpteran tersebut. 


\section{Kesimpulan}

Terjadinya pembakuan Bahasa Indonesia khususnya di pembelajaran memerlukan beberapa tahap. Dari beberapa tahap tersebut responden harus mampu untuk mengimplementasikan dalam kehidupan sehari-hari khususnya di perkuliahan. Karena apabila responden tidak mampu untuk melewati maka hal tersebut tidak akan maksimal dalam proses pembakuan pembakuan Bahasa Indonesia. Pembakuan bahasa merupakan sikap masyarakat atau responden terhadap ragam bahasa yang dilakukan secara beberapa tahap. Istilah dalam pembelajaran Bahasa Indonesia juga dapat diartikan sebagai yang mempunyai makna terbatas dan dapat digunakan secara umum. Berdasarkan implementasi pembelajaran yang sudah dilaksanakan. Responden masih dalam tahap proses belajar untuk menggunakan pembakuan perisitilahan tersebut. Dengan adanya pembakuan istilah computer ke Bahasa Indonesia, bertujuan untuk mengaplikasikan EYD dan pembakuan bahasa dapat dipergunakan sebagaimana mestinya. Untuk merubah menjadi kebiasaan menulis dengan menggunakan pembakuan Bahasa Indonesia memang membutuhkan latihan dalam menerapkan pembakuan tersebut. Responden selama ini hanya sekadar mengerjakan tugas dan mengetik saja, tetapi tidak pernah menghiraukan semua pembakuan istilah Bahasa Indonesia. Pembakuan peristilahan perkomputeran untuk Bahasa Indonesia sangat penting keberadaanya. 
Implementasi Pembakuan Peristilahan Perkomputeran dalam Bahasa Indonesia

\section{BIBLIOGRAFI}

Cholik, C. A. (2017). Pemanfaatan Teknologi Informasi Dan Komunikasi Untuk Meningkatkan Pendidikan Di Indonesia. Syntax Literate; Jurnal Ilmiah Indonesia, 2(6), 21-30.

Lexy. J.Moeloeng. (2009). Metodologi Penelitian Kualitatif. Remaja Rosdakarya.

Mahsun. (2011). Metode Penelitian Bahasa. Rajawali Pers.

Rizkiansyah, R. A., \& Rustono, R. (2017). Perilaku berbahasa pengembang perumahan, pengelola hotel, dan pengelola toko. Seloka: Jurnal Pendidikan Bahasa Dan Sastra Indonesia, 6(1), 25-33.

Setiawati, S. (2016). Penggunaan Kamus Besar Bahasa Indonesia (KBBI) dalam Pembelajaran Kosakata Baku dan Tidak Baku pada Siswa Kelas IV SD. Jurnal Gramatika, 2(1), 80391. 